\title{
Article \\ Implementing an Antimicrobial Stewardship Programme to Improve Adherence to a Perioperative Prophylaxis Guideline
}

\author{
Nehad J. Ahmed ${ }^{1,2}$, Ziyad S. Almalki ${ }^{1}\left(\mathbb{D}\right.$, Abdullah A. Alfaifi ${ }^{1}\left(\mathbb{D}\right.$, Ahmed M. Alshehri $^{1}$ (D),

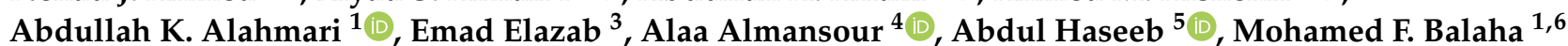 \\ and Amer H. Khan 2,*(D)
}

1 Clinical Pharmacy Department, College of Pharmacy, Prince Sattam Bin Abdulaziz University, Al-Kharj 16273, Saudi Arabia; n.ahmed@psau.edu.sa (N.J.A.); z.almalki@psau.edu.sa (Z.S.A.); a.alfaifi@psau.edu.sa (A.A.A.); ah.alshehri@psau.edu.sa (A.M.A.); a.alahmari@psau.edu.sa (A.K.A.); m.balaha@psau.edu.sa (M.F.B.)

2 Discipline of Clinical Pharmacy, School of Pharmaceutical Sciences, Universiti Sains Malaysia, George Town 11800, Penang, Malaysia

3 Infectious Diseases Department, Al-Kharj Military Industries Corporation Hospital, Al-Kharj 16417, Saudi Arabia; emad.m.elazab@gmail.com

4 Health Sciences Institute, Near East University, North Nicosia 99138, Cyprus; alamansour982@gmail.com

5 Clinical Pharmacy Department, College of Pharmacy, Umm Al-Qura University, Mecca 21955, Saudi Arabia; amhaseeb@uqu.edu.sa

6 Pharmacology Department, Faculty of Medicine, Tanta University, El-Gish Street, Tanta 31527, Egypt

* Correspondence: dramer@usm.my or dramer2006@gmail.com; Tel.: +60-4-6533888 (ext. 5012)

Citation: Ahmed, N.J.; Almalki, Z.S.; Alfaifi, A.A.; Alshehri, A.M.;

Alahmari, A.K.; Elazab, E.;

Almansour, A.; Haseeb, A.; Balaha, M.F.; Khan, A.H. Implementing an Antimicrobial Stewardship

Programme to Improve Adherence to

a Perioperative Prophylaxis

Guideline. Healthcare 2022, 10, 464.

https://doi.org/10.3390/

healthcare10030464

Academic Editor: Farhad Kamali

Received: 29 January 2022

Accepted: 28 February 2022

Published: 1 March 2022

Publisher's Note: MDPI stays neutral with regard to jurisdictional claims in published maps and institutional affiliations.

Copyright: (c) 2022 by the authors. Licensee MDPI, Basel, Switzerland. This article is an open access article distributed under the terms and conditions of the Creative Commons Attribution (CC BY) license (https:// creativecommons.org/licenses/by/ $4.0 /)$.

\begin{abstract}
Perioperative antimicrobial prophylaxis is effective in reducing the rate of surgical site infections (SSIs); however, non-adherence to surgical antimicrobial prophylaxis protocols can lead to several negative outcomes. We performed a before-and-after intervention study with the aim of improving the process outcome, including adherence to guidelines. Another objective of this study was to investigate improvement in patient outcomes as a result of adherence to a surgical antimicrobial prophylaxis programme. The indicators of improved patient outcomes were a reduction in overall SSI rate and the decreased cost of antibiotics. SSI rate was calculated as a percentage by dividing the number of SSIs by the total number of surgeries and then multiplying the value obtained by $100 \%$. The interventions implemented in the surgical antimicrobial prophylaxis programme included establishment of a guideline, educational sessions, and a monthly revision of prescriptions. Our findings show that implementation of the interventions resulted in reduced antibiotic consumption, a considerable decrease in the cost of prophylaxis, and a decrease in the incidence of SSIs.
\end{abstract}

Keywords: antimicrobial stewardship; surgical site infection; surgical antimicrobial prophylaxis

\section{Introduction}

Surgical site infections (SSIs) are the most common healthcare-associated infections that occur among surgical patients. It is reported that SSIs lead to prolonged hospital stay, readmission to the hospital, and increased mortality and morbidity rates [1]. SSIs are defined as postoperative infections that occur within 30 days after undergoing a surgical procedure, or within 1 year after placement of a permanent implant [2]. It is indicated in a European Centre for Disease Prevention and Control report that the cumulative incidence of SSIs mainly depends on the type of surgical procedure; the highest rates have been reported for open colorectal and laparoscopic colorectal operations (10.1\% and $6.4 \%$, respectively), followed by open cholecystectomy (3.9\%) and coronary artery bypass graft (2.6\%) [2] Studies on SSIs have largely focused on surgeries performed on the gastrointestinal tract, which can result in higher SSI rates compared to other procedures. Among the different types of gastrointestinal surgeries, colorectal surgery is the most concerning regarding the development of SSIs due to the presence of multiple microbes in the colon and rectum [3]. 
The number of bacteria and proportion of anaerobic bacteria progressively increase along the gastrointestinal tract; therefore, SSIs that develop after gastrointestinal surgeries must be treated based on the sites at which the procedures were performed [4].

Perioperative antimicrobial prophylaxis has been shown to be effective in reducing the rate of SSIs after surgical procedures [5]. However, inappropriate implementation of surgical antimicrobial prophylaxis, in terms of prolonged duration of the prophylactic treatment in addition to the use of broad-spectrum antibiotics, can result in the development of antibiotic resistance as well as high treatment costs [6]. Moreover, inappropriate timing of surgical antimicrobial prophylaxis can lead to a decrease in the efficacy of the prophylaxis [7]. Therefore, the quality of prophylaxis has been the subject of several audits [8-12] and interventional studies [13-20], and numerous national guidelines have been developed to support appropriate implementation of prophylaxis protocols [21-24].

Antimicrobial stewardship programmes (ASPs) are one of the most important aspects of multipronged interventions to decrease the incidence of SSIs as well as morbidity from antimicrobial-resistant SSIs [25]. The definition for antimicrobial stewardship is an organisational or healthcare system-wide approach to promote and monitor the judicious use of antimicrobials to preserve their future effectiveness [26].

Research on ASP implementation in Saudi Arabia and the effect of antimicrobial stewardship in surgical antibiotic prophylaxis in the region is scarce. To the best of our knowledge, this study is the first to assess the effect of ASP interventions on surgical antimicrobial prophylaxis in Al-Kharj city.

The present study analysed data from various gastrointestinal surgery cases including colorectal surgeries, appendectomies, and bile duct/gall bladder and aimed to investigate the impact of interventions in a surgical antimicrobial prophylaxis programme on process outcome parameters (administration of prophylactic antibiotics) and patient outcome (reduction in SSI rate and cost of consumed antibiotics) at Al-Kharj Military Industries Corporation Hospital (Al-Kharj, Saudi Arabia).

\section{Materials and Methods}

\subsection{Setting}

This study was a prospective interventional study performed at Al-Kharj Military Industries Corporation Hospital (Al-Kharj, Saudi Arabia). The management of this hospital is responsible for developing health care facilities as well as creating health awareness and providing medical care to members of the armed forces and their families.

\subsection{Data Collection}

During the pre- and post-intervention periods, all procedures meeting the inclusion criteria below were included in the analysis. Data were extracted from surgery files and electronic medical records. The data included type of surgery, date of surgery, patient's age and gender, and the prescribed medications.

The durations of the pre- and post-intervention phases of data collection depended on the number of procedures in each phase; as a result, there were variations in the data for the two phases. Activities for the pre-intervention phase started on 1 June 2019 and ended on 15 December 2019, whereas those for the post-intervention phase started on 16 December 2019 and ended on 30 July 2020. To obtain a balanced distribution of the selected procedures, the number of different gastrointestinal surgeries and the age and gender of patients were almost similar before and after the intervention.

\subsection{Inclusion and Exclusion Criteria}

The data on all colorectal surgeries, appendectomies, and bile duct/gall bladder surgeries that were performed during the study period were included in the analysis. Other types of surgeries and surgeries that were conducted before or after the study period were excluded from the analysis. 


\subsection{Interventions}

A guideline on surgical antimicrobial prophylaxis was established, after which implementation of the interventions in the guideline was evaluated. The antibiotic use committee in the hospital announced the guideline to the clinical staff and after that several educational sessions were organized by physicians in the hospital and by an academic staff in the clinical pharmacy department at Prince Sattam Bin Abdulaziz university on antimicrobial stewardship and about the correct use of antibiotics as recommended in surgical antimicrobial prophylaxis guidelines. In addition, monthly reviews of prescribing patterns in the surgery department were conducted to assess improvement in the prescription of antibiotics, with respect to appropriateness of antibiotic selection, route of drug administration, timing of drug administration, antibiotic dose(s), and duration of prophylaxis and after that, feedback was sent to the surgeons.

\subsection{Data Analysis}

The main objectives of this study were to assess improvements in process and patient outcomes as a result of adherence to the guideline and implementation of the recommended protocols. The aim of the surgical antimicrobial prophylaxis programme was to reduce the overall SSI rate and decrease the cost of consumed antibiotics among patients. SSI rate was calculated as a percentage (\%) by dividing the number of SSIs by the total number of surgeries and multiplying the value obtained by $100 \%$.

Antimicrobial use was analysed quantitatively by calculating the defined daily dose (DDD) per 100 procedures. DDDs were obtained from the ATC/DDD Index 2003 of the World Health Organization Collaborating Centre for Drug Statistics Methodology [27]. The cost of consumed antibiotics was calculated by multiplying the DDD/100 surgeries by the cost of the antibiotics. Courses of antimicrobial drugs were reviewed for drug choice, administration route, dosage, and duration and timing of prophylaxis. If no antibiotic prescriptions were recorded, it was assumed that antibiotics had not been administered. All the results have been presented as numbers and percentages. The data were evaluated with the F-test, then were compared with either the two-sample Student's $t$-test or the Mann-Whitney's U test.

\section{Results}

\subsection{Patients' Characteristics}

Table 1 shows the number and percentages of gastrointestinal surgeries that were included in the study with respect to the age ranges and gender of the patients. The number of surgeries before implementation of the guideline was 178; however, 184 surgeries were recorded after implementation of the guideline. More than half of the patients were female, and the majority of them were aged 20-49 years in both the pre- and postintervention phases.

Table 1. Patients who underwent gastrointestinal surgery before and after the intervention.

\begin{tabular}{cccc}
\hline Variable & Category & $\begin{array}{c}\text { Number of Patients in the } \\
\text { Pre-Intervention Phase } \\
\boldsymbol{n} \mathbf{( \% )}\end{array}$ & $\begin{array}{c}\text { Number of Patients in the } \\
\text { Post-Intervention Phase } \\
\boldsymbol{n} \mathbf{( \% )}\end{array}$ \\
\hline \multirow{2}{*}{ Gender } & Male & $85(47.75)$ & $86(46.74)$ \\
& Female & $93(52.25)$ & $98(53.26)$ \\
\hline \multirow{3}{*}{ Age (years) } & $<10$ & $8(4.49)$ & $10(5.43)$ \\
& $10-19$ & $29(16.29)$ & $29(15.76)$ \\
& $20-29$ & $37(20.79)$ & $39(21.20)$ \\
& $30-39$ & $48(26.97)$ & $44(23.92)$ \\
& $40-49$ & $30(16.86)$ & $38(20.65)$ \\
& $50-59$ & $19(10.67)$ & $15(8.15)$ \\
& $>59$ & $7(3.93)$ & $9(4.89)$ \\
\hline
\end{tabular}


Table 2 shows the specific number and percentages of bile and gall bladder surgeries, colorectal surgeries, and appendectomies included in the study. The most performed surgeries in the pre-intervention phase were bile duct/gall bladder surgeries (46.07\%), followed by appendectomies (39.33\%) and colorectal surgeries (14.60\%). The most performed gastrointestinal surgeries in the post-intervention phase were appendectomies (42.93\%), followed by bile duct/gall bladder surgeries (41.31\%) and colorectal surgeries (15.76\%).

Table 2. Surgeries performed on the patients.

\begin{tabular}{ccc}
\hline Type of Surgery & $\begin{array}{c}\text { Number of Surgeries in the } \\
\text { Pre-Intervention Phase } \\
\boldsymbol{n} \mathbf{( \% )}\end{array}$ & $\begin{array}{c}\text { Number of Surgeries in the } \\
\text { Post-Intervention Phase } \\
\boldsymbol{n} \mathbf{( \% )}\end{array}$ \\
\hline $\begin{array}{c}\text { Appendectomy } \\
\text { Bile duct/Gall bladder } \\
\text { surgery }\end{array}$ & $70(39.33)$ & $79(42.93)$ \\
Colorectal surgery & $82(46.07)$ & $76(41.31)$ \\
\hline Total & $26(14.60)$ & $29(15.76)$ \\
\hline
\end{tabular}

\subsection{Appropriateness of Antimicrobials Used for Prophylaxis}

Table 3 shows the frequency at which patients were administered antibiotics. The data show that for all of the included surgeries, patients had to be administered antibiotics. Additionally, antibiotics were not prescribed for the prophylaxis of infections in about $8.99 \%$ of surgeries before the intervention and in about $10.87 \%$ of surgeries after the intervention.

Table 3. Frequency of antibiotic use for gastrointestinal surgeries during the pre- and post-intervention phases.

\begin{tabular}{cccc}
\hline Surgery Type & Use of Antibiotic & $\begin{array}{c}\text { Pre-Intervention } \\
\text { Phase } \\
\boldsymbol{n} \mathbf{( \% )}\end{array}$ & $\begin{array}{c}\text { Post-Intervention } \\
\text { Phase } \\
\boldsymbol{n} \mathbf{( \% )}\end{array}$ \\
\hline \multirow{2}{*}{ Appendectomy } & Yes & $68(97.14)$ & $71(89.87)$ \\
& No & $2(2.86)$ & $8(10.13)$ \\
\hline Bile duct/Gallbladder & Yes & $72(87.80)$ & $68(89.47)$ \\
surgery & No & $10(12.20)$ & $8(10.53)$ \\
\hline \multirow{2}{*}{ Colorectal surgery } & Yes & $22(84.62)$ & $25(86.21)$ \\
& No & $4(15.38)$ & $4(13.79)$ \\
\hline All gastrointestinal & Yes & $162(91.01)$ & $164(89.13)$ \\
surgeries & No & $16(8.99)$ & $20(10.87)$ \\
\hline
\end{tabular}

As shown in Table 4, implementation of the surgical antimicrobial prophylaxis programme resulted in improvement in correct antibiotic use. In addition, there were improvements in the prescription of appropriate antibiotic doses, timing of prophylaxis, choice of route of drug administration, and duration of prophylaxis. The appropriateness of drug selection increased from $51.23 \%$ before the intervention to $53.05 \%$ after the intervention. Appropriateness of drug dose also improved from $32.72 \%$ before the intervention to $53.66 \%$ after the intervention. The appropriateness of timing increased from $64.81 \%$ before implementation of the intervention to $74.39 \%$ after the intervention. Similarly, the appropriateness of route of drug administration and duration of prophylaxis improved from $66.67 \%$ to $76.83 \%$ and from $14.20 \%$ to $19.51 \%$, respectively. 
Table 4. Appropriateness of surgical antimicrobial prophylaxis in the pre- and post-intervention phases.

\begin{tabular}{|c|c|c|c|c|c|}
\hline Surgery Type & $\begin{array}{l}\text { Appropriaten } \\
\text { Antimicrobi }\end{array}$ & $\begin{array}{l}\text { of Surgical } \\
\text { rophylaxis }\end{array}$ & $\begin{array}{l}\text { Pre-Intervention Phase } \\
n(\%)\end{array}$ & $\begin{array}{c}\text { Post-Intervention Phase } \\
n(\%)\end{array}$ & $p$-Value \\
\hline \multirow{10}{*}{ Appendectomy } & \multirow{2}{*}{ Selected drug(s) } & Appropriate & $22(32.35)$ & $29(40.85)$ & \multirow{10}{*}{0.049} \\
\hline & & Inappropriate & $46(67.65)$ & $42(59.15)$ & \\
\hline & \multirow{2}{*}{ Drug dose(s) } & Appropriate & $20(29.41)$ & $29(40.85)$ & \\
\hline & & Inappropriate & 48 (70.59) & $42(59.15)$ & \\
\hline & \multirow{2}{*}{ Timing } & Appropriate & $44(64.71)$ & 55 (77.46) & \\
\hline & & Inappropriate & $24(35.29)$ & $16(22.54)$ & \\
\hline & \multirow{2}{*}{$\begin{array}{l}\text { Route of drug } \\
\text { administration }\end{array}$} & Appropriate & 47 (69.12) & $57(80.28)$ & \\
\hline & & Inappropriate & $21(30.88)$ & $14(19.72)$ & \\
\hline & \multirow{2}{*}{ Duration } & Appropriate & $2(2.94)$ & $5(7.04)$ & \\
\hline & & Inappropriate & $66(97.06)$ & $66(92.96)$ & \\
\hline \multirow{10}{*}{$\begin{array}{l}\text { Bile duct/Gall } \\
\text { bladder surgery }\end{array}$} & \multirow{2}{*}{ Selected drug(s) } & Appropriate & 55 (76.39) & 48 (70.59) & \multirow{10}{*}{0.461} \\
\hline & & Inappropriate & $17(23.61)$ & $20(29.41)$ & \\
\hline & \multirow{2}{*}{ Drug dose(s) } & Appropriate & $24(37.50)$ & $38(55.88)$ & \\
\hline & & Inappropriate & $48(62.50)$ & $30(44.12)$ & \\
\hline & \multirow{2}{*}{ Timing } & Appropriate & $46(63.89)$ & $45(66.18)$ & \\
\hline & & Inappropriate & $26(36.11)$ & $23(33.82)$ & \\
\hline & \multirow{2}{*}{$\begin{array}{l}\text { Route of drug } \\
\text { administration }\end{array}$} & Appropriate & $46(63.89)$ & $46(67.65)$ & \\
\hline & & Inappropriate & $26(36.11)$ & $22(32.35)$ & \\
\hline & \multirow{2}{*}{ Duration } & Appropriate & $16(22.22)$ & $21(30.88)$ & \\
\hline & & Inappropriate & $56(77.78)$ & 47 (69.12) & \\
\hline \multirow{11}{*}{ Colorectal surgery } & \multirow{2}{*}{ Selected drug(s) } & Appropriate & $6(27.27)$ & $10(40.00)$ & \multirow{11}{*}{0.0153} \\
\hline & & Inappropriate & $16(72.73)$ & $15(60.00)$ & \\
\hline & \multirow{2}{*}{ Drug dose(s) } & Appropriate & $9(40.91)$ & $21(84.00)$ & \\
\hline & & Inappropriate & $13(50.09)$ & $4(16.00)$ & \\
\hline & \multirow{2}{*}{ Timing } & Appropriate & $15(68.18)$ & $22(88.00)$ & \\
\hline & & Inappropriate & $7(31.82)$ & $3(12.00)$ & \\
\hline & \multirow{2}{*}{$\begin{array}{l}\text { Route of drug } \\
\text { administration }\end{array}$} & Appropriate & $15(68.18)$ & $23(92.00)$ & \\
\hline & & Inappropriate & $7(31.82)$ & $2(8.00)$ & \\
\hline & \multirow{3}{*}{ Duration } & Appropriate & $5(22.73)$ & $6(24.00)$ & \\
\hline & & Inappropriate & $17(77.27)$ & $19(76.00)$ & \\
\hline & & Inappropriate & $139(85.80)$ & $132(80.49)$ & \\
\hline
\end{tabular}

\subsection{Reduction in SSI Rate}

Table 5 shows the rate of SSIs in 2019 before implementation of the intervention, and in 2020 after implementation of the intervention. The total rate of SSIs in 2019 was $0.41 \%$, whereas that in 2020 was $0.04 \%$ (this percentage was for the total rate of SSIs from all surgeries and not for gastrointestinal surgeries only). 
Table 5. Number of SSIs recorded in 2019 and 2020.

\begin{tabular}{ccccc}
\hline \multirow{2}{*}{ Months } & \multicolumn{2}{c}{$\begin{array}{c}\text { SSIs in 2019 } \\
\text { (Pre-Intervention Period) }\end{array}$} & \multicolumn{2}{c}{$\begin{array}{c}\text { SSIs in 2020 } \\
\text { (Post-Intervention Period) }\end{array}$} \\
\cline { 2 - 5 } & $\begin{array}{c}\text { Number of } \\
\text { SSIs/Total Number } \\
\text { of Surgeries }\end{array}$ & SSI Rate & $\begin{array}{c}\text { Number of } \\
\text { SSIs/Total Number } \\
\text { of Surgeries }\end{array}$ & SSI Rate \\
\hline January-March & $3 / 635$ & $0.47 \%$ & $0 / 666$ & $0.00 \%$ \\
$\begin{array}{c}\text { April-June } \\
\text { July-September } \\
\text { October- }\end{array}$ & $2 / 639$ & $0.31 \%$ & $0 / 469$ & $0.00 \%$ \\
December & $3 / 610$ & $0.49 \%$ & $1 / 550$ & $0.18 \%$ \\
\hline Total & $3 / 811$ & $0.37 \%$ & $0 / 706$ & $0.00 \%$ \\
\hline
\end{tabular}

\subsection{Antimicrobial Use}

According to the guideline, the first drug of choice for bile duct and gall bladder surgeries is cefazolin (the recommended antibiotic); however, if cefazolin is not available, cefuroxime or ceftriaxone (alternative agents) may be used. For colorectal surgeries and appendectomy, patients must be administered cefazolin and metronidazole (the recommended combination); however, if cefazolin is not available, cefuroxime or ceftriaxone and metronidazole (alternative agents) may be used. As shown in Table 6, in the post-intervention phase, the use of intravenous cefazolin increased (from 0 to 7.97 DDD/100 surgeries), whereas the use of intravenous cefuroxime decreased (from 13.76 to $0.27 \mathrm{DDD} / 100$ surgeries). Moreover, the use of intravenous metronidazole increased (from 23.31 to $29.07 \mathrm{DDD} / 100$ surgeries), whereas the total consumption of antibiotics reduced from 920.36 to $788.56 \mathrm{DDD} / 100$ surgeries.

Table 6. Number of patients who were administered different antibiotics before and after the intervention.

\begin{tabular}{|c|c|c|c|c|c|}
\hline Antibiotic & $\begin{array}{c}\text { Route of Drug } \\
\text { Administration }\end{array}$ & $\begin{array}{l}\text { DDD of Antibiotic } \\
\text { before the } \\
\text { Intervention }\end{array}$ & $\begin{array}{c}\text { DDD/100 Surgeries } \\
\text { before the } \\
\text { Intervention }\end{array}$ & $\begin{array}{l}\text { DDD of Antibiotic } \\
\text { after the Intervention }\end{array}$ & $\begin{array}{l}\text { DDD/100 Surgeries } \\
\text { after the Intervention }\end{array}$ \\
\hline Ceftriaxone & Intravenous & 1.50 & 0.84 & 1 & 0.54 \\
\hline Cefuroxime & $\begin{array}{l}\text { Intravenous } \\
\text { Oral }\end{array}$ & $\begin{array}{l}24.5 \\
1414\end{array}$ & $\begin{array}{c}13.76 \\
794.38\end{array}$ & $\begin{array}{l}0.50 \\
994\end{array}$ & $\begin{array}{c}0.27 \\
540.22\end{array}$ \\
\hline Metronidazole & $\begin{array}{l}\text { Intravenous } \\
\text { Oral }\end{array}$ & $\begin{array}{l}41.50 \\
71.4\end{array}$ & $\begin{array}{l}23.31 \\
40.11\end{array}$ & $\begin{array}{c}53.50 \\
63\end{array}$ & $\begin{array}{l}29.07 \\
34.24\end{array}$ \\
\hline Ciprofloxacin & $\begin{array}{l}\text { Intravenous } \\
\text { Oral }\end{array}$ & $\begin{array}{c}2.25 \\
1\end{array}$ & $\begin{array}{l}1.26 \\
0.56\end{array}$ & $\begin{array}{c}0.25 \\
47.50\end{array}$ & $\begin{array}{c}0.14 \\
25.82\end{array}$ \\
\hline Amoxicillin/Clavulanic acid & Oral & 62.12 & 34.90 & 232.53 & 126.38 \\
\hline Cefazolin & Intravenous & 0 & 0 & 14.67 & 7.97 \\
\hline Doxycycline & Oral & 0 & 0 & 42 & 22.83 \\
\hline Trimethoprim/Sulfamethoxazole & Oral & 0 & 0 & 2 & 1.09 \\
\hline Cefprozil & Oral & 20 & 11.24 & 0 & 0 \\
\hline Total & & 1638.27 & 920.36 & 1450.95 & 788.56 \\
\hline
\end{tabular}

As shown in Table 7, the costs of cefuroxime, ceftriaxone, and metronidazole decreased after the intervention, whereas those of ciprofloxacin, Amoxicillin/Clavulanic acid, and cefazolin increased. The maximum estimation of reduction in cost between the preand post-intervention phases was 1783.81 Saudi Riyal (9513.92-7730.11) that is equal to 475.39 United States Dollar ( $p$-value < 0.05). 
Table 7. Antibiotic cost before and after the intervention.

\begin{tabular}{|c|c|c|c|c|c|}
\hline Antibiotics & $\begin{array}{l}\text { Route of Drug } \\
\text { Administration }\end{array}$ & $\begin{array}{l}\text { DDD/100 Surgeries } \\
\text { before the } \\
\text { Intervention }\end{array}$ & $\begin{array}{c}\text { Antibiotic Cost in } \\
\text { the Pre-Intervention } \\
\text { Phase }\end{array}$ & $\begin{array}{l}\text { DDD/100 Surgeries } \\
\text { after the Intervention }\end{array}$ & $\begin{array}{c}\text { Antibiotic Cost in } \\
\text { the Post-Intervention } \\
\text { Phase }\end{array}$ \\
\hline Ceftriaxone & Intravenous & 0.84 & 77.28 & 0.54 & 49.68 \\
\hline Cefuroxime & $\begin{array}{l}\text { Intravenous } \\
\text { Oral }\end{array}$ & $\begin{array}{c}13.76 \\
794.38\end{array}$ & $\begin{array}{l}598.42 \\
6156.45\end{array}$ & $\begin{array}{c}0.27 \\
540.22\end{array}$ & $\begin{array}{c}11.74 \\
4186.71\end{array}$ \\
\hline Metronidazole & $\begin{array}{l}\text { Intravenous } \\
\text { Oral }\end{array}$ & $\begin{array}{l}23.31 \\
40.11\end{array}$ & $\begin{array}{l}736.60 \\
768.11\end{array}$ & $\begin{array}{l}29.07 \\
34.24\end{array}$ & $\begin{array}{l}918.61 \\
655.70\end{array}$ \\
\hline Ciprofloxacin & $\begin{array}{c}\text { Intravenous } \\
\text { Oral }\end{array}$ & $\begin{array}{l}1.26 \\
0.56\end{array}$ & $\begin{array}{c}199.95 \\
7.83\end{array}$ & $\begin{array}{c}0.14 \\
25.82\end{array}$ & $\begin{array}{c}22.22 \\
361.22\end{array}$ \\
\hline Amoxicillin/Clavulanic acid & Oral & 34.90 & 244.30 & 126.38 & 884.66 \\
\hline Cefazolin & Intravenous & 0 & 0 & 7.97 & 89.26 \\
\hline Doxycycline & Oral & 0 & 0 & 22.83 & 531.94 \\
\hline Trimethoprim/Sulfamethoxazole & Oral & 0 & 0 & 1.09 & 18.37 \\
\hline Cefprozil & Oral & 11.24 & 724.98 & 0 & 0 \\
\hline Total & & 920.36 & 9513.92 & 788.56 & 7730.11 \\
\hline
\end{tabular}

\section{Discussion}

Implementation of the surgical antimicrobial prophylaxis programme in the present study resulted in increased compliance of prescribers with the guideline recommendations. It also led to improvements in the correct use of antibiotics, appropriate dose prescription, timing and duration of prophylaxis, and choice of route of administration. However, there was still a problem with the duration of prophylaxis. In a previous study by Segala et al. [28], it was found that after the implementation of an antimicrobial stewardship intervention, the appropriateness of prophylaxis duration was still not optimal, which was the most reported reason for non-compliant prescribing in the post-interventional survey of their study. Elyasi et al. [29] have also reported that there was a significant reduction in incorrect use of antibiotics after the implementation of an evidence-based guideline for gastrointestinal surgeries in a teaching hospital. Additionally, implementation of the guideline resulted in a reduction in the duration of antibiotic prophylaxis and a decrease in the prescription of inappropriate antibiotic doses, although this was not significant [29].

Implementation of the prophylaxis programme in the present study resulted in decreases in SSI rate, overall antibiotic consumption, and the cost of antibiotics. Sarang et al. [25] have reported that implementing SSI prevention guidelines, including proper antimicrobial prophylaxis, in two tertiary-care hospitals in Mumbai resulted in a significant decrease in prophylaxis costs; however, the SSI rates did not differ from those obtained after following the same international standards. A study conducted by van Kasteren et al. [30] in a multisite, interventional study in Dutch hospitals revealed that intervention implementation led to improved quality of surgical antimicrobial prophylaxis as well as a reduction in antibiotic use and cost; however, there was an insignificant reduction in SSIs. Similarly, optimising antibiotic prophylaxis resulted in an insignificant reduction in the overall SSI rate from $5.4 \%$ to $4.5 \%$ in another study [31]. Furthermore, Fujibayashi et al. [32] have suggested that revising all relevant clinical pathways in invasive therapies may be highly effective in reducing antibiotic consumption and shortening the duration of antibiotic administration. It was found in the study conducted by Fujibayashi et al. [32] that the incidence of SSIs was not significantly different before and after the revisions made.

A study performed in a private hospital in Saudi Arabia by Kilan et al. [33] showed that implementation of interventions that could improve surgical antibiotic prophylaxis resulted in improved antibiotic selection, dosing, and timing of prophylaxis from $47.3 \%$ to $82.2 \%$ in patients undergoing gastrointestinal surgery $(p<0.001)$ [33]. Additionally, implementation of the interventions led to a reduction in SSI rate, although this change was not statistically significant. 


\section{Limitations}

The main limitation of the present study was that the intervention was not implemented in a control group, as that was considered unethical. Second limitation was that some of the resulting changes were not statistically significant because there was a limited number of gastrointestinal surgeries that were performed in the hospital.

\section{Conclusions}

Implementation of the surgical antimicrobial prophylaxis programme included the establishment of a guideline, educational sessions, and a monthly revision of prescriptions. Our findings show that implementation of the programme resulted in decreases in antibiotic consumption, antibiotic prophylaxis cost, and the incidence of SSIs.

Author Contributions: Conceptualisation, N.J.A. and Z.S.A.; methodology, N.J.A.; software, A.M.A.; validation, A.K.A., E.E. and N.J.A.; formal analysis, A.A., N.J.A. and A.K.A.; investigation, N.J.A.; resources, A.M.A. and E.E.; data curation, A.A., Z.S.A. and A.A.A.; writing-original draft preparation, N.J.A.; writing-review and editing, A.H. and A.H.K.; visualisation, A.A.A. and M.F.B.; supervision, A.H.K. and A.H.; project administration, N.J.A. and Z.S.A.; funding acquisition, N.J.A. and M.F.B. All authors have read and agreed to the published version of the manuscript.

Funding: This research received no external funding.

Institutional Review Board Statement: The study was conducted in accordance with the Declaration of Helsinki, and approved by the Institutional Review Board of Al-Kharj Military Industries Corporation Hospital (protocol code 4101728 and date of approval).

Informed Consent Statement: Not applicable.

Data Availability Statement: Not applicable.

Conflicts of Interest: The authors declare no conflict of interest.

\section{References}

1. Geubbels, E.L.; Mintjes-de Groot, A.J.; van den Berg, J.M.J.; de Boer, A.S. An operating surveillance system of surgical-site infections in The Netherlands: Results of the PREZIES national surveillance network. Infect. Control Hosp. Epidemiol. 2000, 21, 311-318. [CrossRef] [PubMed]

2. European Centre for Disease Prevention and Control. Healthcare-Associated Infections: Surgical Site Infections-Annual Epidemiological Report for 2017. Available online: https://www.ecdc.europa.eu/en/publications-data/healthcare-associatedinfections-surgical-site-infections-annual-1 (accessed on 5 July 2021).

3. Wang, Z.; Chen, J.; Wang, P.; Jie, Z.; Jin, W.; Wang, G.; Li, J.; Ren, J. Surgical site infection after gastrointestinal surgery in China: A multicenter prospective study. J. Surg. Res. 2019, 240, 206-218. [CrossRef]

4. Woods, R.K.; Dellinger, E.P. Current guidelines for antibiotic prophylaxis of surgical wounds. Am. Fam. Phys. 1998, 57, 2731-2740.

5. Polk, H.C., Jr.; Christmas, A.B. Prophylactic antibiotics in surgery and surgical wound infections. Am. Surg. 2000, 66, 105-111.

6. Harbarth, S.; Samore, M.H.; Lichtenberg, D.; Carmeli, Y. Prolonged antibiotic prophylaxis after cardiovascular surgery and its effect on surgical site infections and antimicrobial resistance. Circulation 2000, 101, 2916-2921. [CrossRef]

7. Classen, D.C.; Evans, R.S.; Pestotnik, S.L.; Horn, S.D.; Menlove, R.L.; Burke, J.P. The timing of prophylactic administration of antibiotics and the risk of surgical-wound infection. N. Engl. J. Med. 1992, 326, 281-286. [CrossRef] [PubMed]

8. Zoutman, D.; Chau, L.; Watterson, J.; Mackenzie, T.; Djurfeldt, M. A Canadian survey of prophylactic antibiotic use among hip-fracture patients. Infect. Control Hosp. Epidemiol. 1999, 20, 752-755. [CrossRef] [PubMed]

9. Vaisbrud, V.; Raveh, D.; Schlesinger, Y.; Yinnon, A.M. Surveillance of antimicrobial prophylaxis for surgical procedures. Infect. Control Hosp. Epidemiol. 1999, 20, 610-613. [CrossRef]

10. Heineck, I.; Ferreira, M.B.; Schenkel, E.P. Prescribing practice for antibiotic prophylaxis for 3 commonly performed surgeries in a teaching hospital in Brazil. Am. J. Infect. Control 1999, 27, 296-300. [CrossRef]

11. Burke, J.P. Maximizing appropriate antibiotic prophylaxis for surgical patients: An update from LDS Hospital, Salt Lake City. Clin. Infect. Dis. 2001, 33, S78-S83. [CrossRef]

12. Bratzler, D.W.; Houck, P.M.; Richards, C.; Steele, L.; Dellinger, E.P.; Fry, D.E.; Wright, C.; Ma, A.; Carr, K.; Red, L. Use of antimicrobial prophylaxis for major surgery: Baseline results from the National Surgical Infection Prevention Project. Arch. Surg. 2005, 140, 174-182. [CrossRef] [PubMed]

13. Everitt, D.E.; Soumerai, S.B.; Avorn, J.; Klapholz, H.; Wessels, M. Changing surgical antimicrobial prophylaxis practices through education targeted at senior department leaders. Infect. Control Hosp. Epidemiol. 1990, 11, 578-583. [CrossRef] 
14. Gyssens, I.C.; Geerligs, I.E.J.; Dony, J.M.J.; van der Vliet, J.A.; van Kampen, A.; van den Broek, P.J.; Hekster, Y.A.; van der Meer, J.W.M. Optimising antimicrobial drug use in surgery: An intervention study in a Dutch university hospital. J. Antimicrob. Chemother. 1996, 38, 1001-1012. [CrossRef]

15. Gyssens, I.C.; Geerligs, I.E.; Nannini-Bergman, M.G.; Knape, J.T.; Hekster, Y.A.; van der Meer, J.W. Optimizing the timing of antimicrobial prophylaxis in surgery: An intervention study. J. Antimicrob. Chemother. 1996, 38, 301-308. [CrossRef]

16. Welch, L.; Teague, A.C.; Knight, B.A.; Kenney, A.; Hernandez, J.E. A quality management approach to optimizing delivery and administration of preoperative antibiotics. Clin. Perform. Qual. Health Care 1998, 6, 168-171.

17. Schell, J.A.; Bynum, C.G.; Fortune, G.J.; Laiben, G.R.; Chang, Y.J.; Pirner, J.A. Perioperative antibiotics in nonemergency bowel surgery: A quality improvement project. South. Med. J. 1998, 91, 900-908. [CrossRef]

18. Talon, D.; Mourey, F.; Touratier, S.; Marie, O.; Arlet, G.; Decazes, J.M.; Schlemmer, B.; Faure, P. Evaluation of current practices in surgical antimicrobial prophylaxis before and after implementation of local guidelines. J. Hosp. Infect. 2001, 49, 193-198. [CrossRef]

19. Weinberg, M.; Fuentes, J.M.; Ruiz, A.I.; Lozano, F.W.; Angel, E.; Gaitan, H.; Goethe, B.; Parra, S.; Hellerstein, S.; Ross-Degnan, D.; et al. Reducing infections among women undergoing cesarean section in Colombia by means of continuous quality improvement methods. Arch. Intern. Med. 2001, 161, 2357-2365. [CrossRef] [PubMed]

20. Prado, M.A.M.B.; Lima, M.P.J.S.; Irene da Rocha, H.G.; Bergsten-Mendes, G. The implementation of a surgical antibiotic prophylaxis program: The pivotal contribution of the hospital pharmacy. Am. J. Infect. Control 2002, 30, 49-56. [CrossRef] [PubMed]

21. Dellinger, E.P.; Gross, P.A.; Barrett, T.L.; Krause, P.J.; Martone, W.J.; McGowan, J.E., Jr.; Sweet, R.L.; Wenzel, R.P. Quality standard for antimicrobial prophylaxis in surgical procedures. Infect. Control Hosp. Epidemiol. 1994, 15, 182-188. [CrossRef]

22. van Kasteren, M.E.; Gyssens, I.C.; Kullberg, B.J.; Bruining, H.A.; Stobberingh, E.E.; Goris, R.J. Optimizing antibiotics policy in the Netherlands. V. SWAB guidelines for perioperative antibiotic prophylaxis. Foundation Antibiotics Policy Team. Ned. Tijdschr. Geneeskd. 2000, 144, 2049-2055.

23. Scottish Intercollegiate Guidelines Network. Antibiotic Prophylaxis in Surgery. Available online: http://www.sign.ac.uk/ guidelines/fulltext/45/index.html (accessed on 5 July 2021).

24. Bratzler, D.W.; Houck, P.M.; Surgical Infection Prevention Guidelines Writers Workgroup. Antimicrobial prophylaxis for surgery: An advisory statement from the National Surgical Infection Prevention Project. Clin. Infect. Dis. 2004, 38, 1706-1715. [CrossRef]

25. Sarang, B.; Tiwary, A.; Gadgil, A.; Roy, N. Implementing antimicrobial stewardship to reduce surgical site infections: Experience and challenges from two tertiary-care hospitals in Mumbai, India. J. Glob. Antimicrob. Resist. 2020, 20, 105-109. [CrossRef]

26. Nathwani, D. Overview of AMR. In Antimicrobial Stewardship from Principles to Practice; Nathwani, D., Ed.; British Society for Antimicrobial Chemotherapy: Birmingham, UK, 2018.

27. WHO Collaborating Centre for Drug Statistics Methodology. Anatomical Therapeutic Chemical (ATC) Classification Index, Including Defined Daily Doses (DDDs) for Plain Substances. Available online: http:/ /WHOcc.no/atcddd (accessed on 5 July 2021).

28. Segala, F.V.; Murri, R.; Taddei, E.; Giovannenze, F.; Del Vecchio, P.; Birocchi, E.; Taccari, F.; Cauda, R.; Fantoni, M. Antibiotic appropriateness and adherence to local guidelines in perioperative prophylaxis: Results from an antimicrobial stewardship intervention. Antimicrob. Resist. Infect. Control 2020, 9, 164. [CrossRef]

29. Elyasi, S.; Fattahi Masum, A.; Bahreyni, A.; Samani, S.S.; Atamanesh, A.; Abdollahi, A.; Mousavi, M. Evaluation of antibiotic prophylaxis for gastrointestinal surgeries in a teaching hospital: An interventional pre-post study. J. Perioper. Pract. 2019, 2019, 1750458919825583. [CrossRef] [PubMed]

30. van Kasteren, M.E.E.; Mannien, J.; Kullberg, B.-J.; de Boer, A.S.; Nagelkerke, N.J.; Ridderhof, M.; Wille, J.C.; Gyssens, I.C. Quality improvement of surgical prophylaxis in Dutch hospitals: Evaluation of a multi-site intervention by time series analysis. J. Antimicrob. Chemother. 2005, 56, 1094-1102. [CrossRef] [PubMed]

31. Manniën, J.; van Kasteren, M.E.E.; Nagelkerke, N.J.; Gyssens, I.C.; Kullberg, B.J.; Wille, J.C.; de Boer, A.S. Effect of optimized antibiotic prophylaxis on the incidence of surgical site infection. Infect. Control Hosp. Epidemiol. 2006, 27, 1340-1346. [CrossRef] [PubMed]

32. Fujibayashi, A.; Niwa, T.; Tsuchiya, M.; Takeichi, S.; Suzuki, K.; Ohta, H.; Yonetamari, J.; Niwa, A.; Yamamoto, M.; Hatakeyama, D.; et al. Antimicrobial stewardship intervention for the clinical pathways improves antimicrobial prophylaxis in surgical or nonsurgical invasive therapies. Int. J. Clin. Pract. 2019, 73, e13293. [CrossRef]

33. Kilan, R.; Moran, D.; Eid, I.; Okeahialam, C.; Quinn, C.; Binsaddiq, W.; Williams, T.; Johnson, M.H. Improving antibiotic prophylaxis in gastrointestinal surgery patients: A quality improvement project. Ann. Med. Surg. 2017, 20, 6-12. [CrossRef] 